\title{
Moçambique - 30 anos de Independência: no passado, o futuro era melhor? ${ }^{1}$
}

\author{
Mia Couto \\ Escritor moçambicano
}

asci e cresci numa pequena cidade colonial, num mundo que já morreu. Desde cedo, aprendi que devia viver contra o meu próprio tempo. A realidade colonial estava ali, no quotidiano, arrumando os homens pela raça, empurrando os africanos para além dos subúrbios. Eu mesmo, privilegiado pela minha cor da pele, era tido como um "branco de segunda categoria". Todos os dias me confrontava com a humilhação dos negros descalços e obrigados a sentarem-se no banco de trás dos autocarros, no banco de trás da Vida. Na minha casa vivíamos paredes-meias com o medo, perante a ameaça de prisão que pesava sobre o meu pai que era jornalista e nos ensinava a não baixar os olhos perante a injustiça. A independência nacional era para mim o final desse universo de injustiças. Foi por isso que abracei a causa revolucionária como se fosse uma predestinação. Cedo me tornei um membro da Frente de Libertação de Moçambique e a minha vida foi, durante um tempo, guiada por um sentimento épico de estarmos criando uma sociedade nova.

No dia da Independência de Moçambique eu tinha 19 anos. Alimentava, então, a expectativa de ver subir num mastro uma bandeira para o meu país. Eu acreditava, assim, que o sonho de um povo se poderia traduzir numa simples bandeira. Em 1975, eu era jornalista, o mundo era a minha igreja, os homens a minha religião. E tudo era ainda possível.

$\mathrm{Na}$ noite de 24 de Junho, juntei-me a milhares de outros moçambicanos no Estádio da Machava para assistir à proclamação da Independência Naci-

\footnotetext{
${ }^{1}$ Texto pronunciado por Mia Couto em Conferência realizada em Deza Traverse Suíça, por ocasião dos 30 anos de Independência de Moçambique. Junho 2005.
} 
onal, que seria anunciada na voz rouca de Samora Moisés Machel. O anúncio estava previsto para a meia-noite em ponto. Nascia o dia, alvorecia um país. Passavam 20 minutos da meia-noite e ainda Samora não emergira no pódio. De repente, a farda guerrilheira de Samora emergiu entre os convidados. Sem dar confiança ao rigor do horário, o Presidente proclamou: "às zero horas de hoje, 25 de Junho..”. Um golpe de magia fez os ponteiros recuarem. A hora ficou certa, o tempo ficou nosso.

Não esqueço nunca os rostos iluminados por um irrepetível encantamento, não esqueço os gritos de euforia, os tiros dos guerrilheiros anunciando o fim de todas as guerras. Havia festa, a celebração de sermos gente, termos chão e merecermos céu. Mais que um país celebrávamos um outro destino para nossas vidas. Quem tinha esperado séculos não dava conta de vinte minutos a mais.

Trinta anos depois poderíamos ainda fazer recuar os ponteiros do tempo? A mesma crença mora ainda no cidadão moçambicano? Não, não mora. Nem podia morar. Em 1975, nós mantínhamos a convicção legítima, mas ingénua de que era possível, no tempo de uma geração, mudarmos o mundo e redistribuirmos felicidade. Não sabíamos quanto o mundo é uma pegajosa teia onde uns são presas e outros predadores.

Trinta anos é quase nada na história de um país. Estamos já distantes da injustiça colonial. Mas estamos ainda longe de cumprir o sonho que nos fez cantar e dançar na noite de 25 de Junho. Uma parte dessa expectativa ficou por realizar. Hoje já não acorreríamos com a mesma fé para celebrar uma nova anunciação. Mas isso não quer dizer que estamos menos disponíveis para a crença. Estaremos, sim, mais conscientes que tudo pede um caminho e um tempo.

Poderemos recorrer a explicações, apontar dedos acusadores. Tudo isso será pouco produtivo. Não se pode esperar que um país saído do atraso da dominação colonial possa realizar aquilo que velhas nações independentes estão ainda construindo. Moçambique está aprendendo a ser soberano num mundo que aceita muito pouco a soberania dos outros. O céu que parecia infinito foi ficando estreito para as chamadas pequenas bandeiras.

No mesmo ano em que se desintegrava o império colonial português, em 1975, os Estados Unidos da América eram derrotados no Vietname. O tempo parecia correr a favor dos povos "pequenos", capazes de enfrentar a arrogância dos poderosos. Essas vitórias criaram a ilusão de que um mundo mais 
justo estava despontando. Mas o sistema mundial cedo se reajustou desses revezes. A Independência de Moçambique teve que enfrentar uma dualidade: representou uma ruptura com o colonialismo mas, ao mesmo tempo, funcionou como um passo para uma maior integração num sistema capitalista que se globalizava. A essa condição ambivalente não poderíamos escapar.

Meus senhores e minha senhoras,

Caros amigos,

No meu romance Terra Sonâmbula criei um personagem que, por nascer no dia da Independência, a vinte e cinco de Junho, foi baptizado de Junhito. A história decorre no decurso da nossa guerra civil que se prolongou durante 16 anos.

Certa noite, o pai de Junhito é assaltado por um pressentimento: o seu filho iria morrer em breve. Era isso o que a guerra reclamava: a morte desse que nascera em Junho. Para salvar o filho, a família resolveu transferi-lo para a capoeira que ficava no quintal. Ali Junhito aprenderia a comportar-se como as galinhas, comendo as sobras e dormindo ao relento. Resignado a sobreviver sem glória, sem brilho, sem substância.

Junhito foi-se tornando numa sombra e, em casa, os familiares estavam proibidos até de mencionar o seu nome. A mãe, mesmo ela, parecia conformada. Contudo, às escondidas da noite, ela visitava a capoeira. Sentava-se no escuro e cantava uma canção de embalar, a mesma que servira para adormecer os outros irmãos. Junhito, de início, acompanhava a mãe no canto. Mas depois, o menino já nem sabia soletrar as humanas palavras. Esganiçava uns cóós e ajeitava a cabeça por baixo do braço. E assim adormecia, sonhando que, certa vez, teria sido um homem.

A metáfora no romance é simples, quase linear. $\mathrm{Na}$ altura, eu denunciava a nossa progressiva perda de soberania, e uma crescente domesticação do nosso espírito de ousadia. Poderíamos ser nação mas não demasiado, poderíamos ser povo mas apenas se bem comportado.

Num processo difícil e conflituoso, Moçambique criou a reputação de ser um caso de excepção em África. Esse bom-nome, devo dizer, é merecido. Esse prestígio foi conquistado, não é uma prenda de nenhum paternalismo. Fomos capazes de produzir a Paz. Fomos capazes de criar democracia formal, de construir estabilidade e de garantir liberdades de expressão e de pen- 
samento. Tenho orgulho nesse processo. Mas tenho também receio. Porque o caminho que percorremos não foi exactamente escolhido por nós, nem está sendo testado à medida da nossa vontade. $\mathrm{O}$ nosso êxito não pode continuar a ser medido apenas pelo sucesso da aplicação de um directório de receitas políticas e financeiras. Ao contrário, deveríamos ser valorizados pelo modo como repensamos criativamente o nosso lugar no mundo.

Nos gloriosos anos da luta de libertação nós gritávamos "Independência ou Morte, Venceremos". Hoje sabemos: a independência não é mais do que a possibilidade de escolhermos as nossas dependências. Na década de 70, o mundo oferecia a possibilidade de diferentes opções e alianças estratégicas. Hoje as economias nacionais perfilam-se perante um modelo sem alternativa. Escolhemos o que outros escolheram por nós. Uma parte da nossa alma foi já, mesmo sem o sabermos, conduzida para a capoeira e ali esquece a irreverência, a originalidade e o desejo de ser único.

A redução da soberania não é um processo que esteja atingindo especificamente Moçambique. É um processo generalizado. Todas nações são hoje menos nacionais, todo o cidadão é menos dono do si mesmo. Uns dizem que, agora, somos todos mundo. Mas ninguém pode ser do mundo se não tiver a sua pequena aldeia.

\section{Como a Europa vê África}

Os continentes são, sobretudo, representações feitas e refeitas de acordo com os tempos. A África de hoje é uma co-produção euro-afro-americana. A versão mais recente dessa co-produção é marcada pela morte e decadência. Cadeias de TV estão confirmando essa agonia, entre doenças e guerras. $\mathrm{O}$ excesso de imagens dos dramas de África teve um efeito perverso: o continente deixou de ser visível. Perdeu visibilidade porque tudo parece estar já visto. Aos olhos do resto do mundo, África (ou uma parte dela) deixou de existir. Do mapa cor-de-rosa se passou ao monocromático mapa do desespero.

O apocalipse africano esteve demasiado tempo na montra, foi excessivamente filmado, fotografado, torcido e retorcido para uso da compaixão. Deixou de existir disponibilidade para entender o que está por detrás dessas imagens. Afinal, a fome a guerra são apenas os sinais de uma tragédia mais 
funda e mais antiga. Essa tragédia assenta em razões internas mas assenta também no lugar periférico de África e nas trocas desiguais do comércio internacional.

Uma certa esquerda europeia transitou da simpatia para um pessimismo militante. A lágrima solidária foi substituída pela indiferença e pelo descrédito. Os africanos, por seu turno, foram eternizando um sentimento de culpabilização dos outros, acreditando tratar-se da continuação de um "complot" antigo para os dizimar.

De um e outro lado, se acumularam desilusões e impaciências. Uma mesma ignorância do Outro foi transitando ao longo da História. Aos profetas do socialismo seguiram-se os profetas do neoliberalismo agitando apressadas receitas financeiras para salvar os pobres. Mas a pobreza insiste, teimosa como uma incurável doença que nos devora do outro lado do Mediterrâneo.

A opção para os países doadores parece simples: dar mais ou deixar de dar. As recentes notícias mostram que, nos próximos tempos, se irá dar um pouco mais. Pelo menos em algumas nações terá vencido a alternativa mais humanitária. Contudo, poucos se interrogarão sobre a necessidade de mudar a qualidade da relação entre o Norte e o Sul.

\section{Como nós vemos a Suíça}

A Suiça já foi para muitos moçambicanos não um país mas o nome de uma missão religiosa. A Missão Suiça implantou-se no Sul de Moçambique, enfrentando terríveis suspeitas do regime colonial português. Henri Junod foi expulso de Moçambique em 1895 porque ensinava as chamadas "línguas dos nativos”. O missionário ajudava moçambicanos como Eduardo Mondlane a moçambicanizarem-se enquanto, nesse processo, ele mesmo se africanizava, acabando por solicitar que fosse enterrado em terras de Moçambique.

Setenta anos mais tarde, um outro suíço converteu-se numa figura de dimensão quase mitológica. Tratava-se do médico René Gagnaux, uma espécie de filantropo da nova vaga, um homem que dedicou a sua vida a atender os mais pobres. A Suíça, para muitos, era a terra do Gagnaux. Um dos seus filhos, agora moçambicano, lidera uma das principais forças políticas em nível da cidade de Maputo. 
Hoje temos da Suiça uma percepção mais moderna e designamo-la por via de um nome curioso: "país doador". O mundo está hoje dividido entre os que dão e os que recebem. Como se fosse uma condição natural, genética, perpétua. Nós, os receptores daquilo que se chama "ajuda" já tivemos outros nomes: fomos Terceiro Mundo, países em vias desenvolvimento, territórios do Sul, países sub-desenvolvidos, nações da periferia.

A dança dos nomes não terminou. Agora, no quadro do politicamente corrigido, nós temos, pela primeira vez, o direito de partilhar de um mesmo nome: somos ambos, ricos e pobres, chamados de "parceiros". Este novo nome é mais simpático mas ele colide com uma questão de princípio: não se resolve nas palavras aquilo que não está resolvido na substância.

\section{As mútuas atribuições de culpas}

O embaixador da Suiça em Moçambique, o meu amigo Dr. Adrian Hadorn, é testemunha da minha insistente intervenção em Moçambique para combater a tendência de vitimização por parte dos africanos. Enquanto continuarmos culpando os europeus pelos nossos próprios falhanços não seremos capazes de nos olharmos para nós próprios como principal motor da mudança. Assumir a condição de sujeito histórico: esse era o maior e mais instigante desafio da Independência Nacional.

É infindável a soma de argumentos para justificar a cleptocracia e a corrupção dentro de continente africano. Alguns intelectuais africanos vêm na importação de modelos externos a origem de todos os males. Esta justificação encontra espaço em alguns doadores. Na linguagem moderna dos relatórios dos consultores este problema seria assim reportado: "falta de ownership das reformas estruturais". Impostas de fora, essas reformas não poderiam ser implementadas. Mas tudo indica que, ao contrário, parte dessas reformas foi rápida e profundamente apropriada por elites nacionais que as usaram a favor do seu próprio enriquecimento. $\mathrm{O}$ problema não parece estar na origem dos modelos mas na sua natureza política. Os africanos africanizaram a mandioca. As elites fizeram o mesmo com as reformas estruturais.

Se alguns africanos acham que a culpa é apenas dos europeus, no sentido inverso, europeus há que acreditam que a culta cabe apenas aos africanos. Uma 
relação mais saudável entre uns e outros obrigaria a rupturas profundas, implicava poder começar de novo. Mas esse retorno ao grau zero não existe na História. Compete-nos questionar os pressupostos do nosso relacionamento recíproco.

Elegi para este pequeno texto alguns tópicos soltos. Não sou economista, sou um escritor cuja paixão reside num mundo que não existe. Mas não posso focar indiferente perante alguns assuntos que determinam nosso destino comum. Eis algumas das interrogações que gostaria de partilhar convosco.

\section{O falso sentimento de desperdício}

A opinião pública na Europa e nos EUA mantém a idéia de que África pode sair da situação de crise se gerir bem os fundos doados. A ajuda apenas é insuficiente porque é mal usada.

É certo que parte das doações tem sido desviada em benefício de elites minoritárias. Algumas dessas fortunas roubadas estão aqui, bem no coração da Europa, na forma de criminosas contas bancárias. Mas a grande verdade é que, mesmo bem usada, a actual ajuda não resolveria os problemas vitais das nações empobrecidas. Pelo contrário, o actual quadro da ajuda poderá estar agravando a condição de miséria do Terceiro Mundo.

Regressemos à idéia dominante de que os valores da ajuda são astronómicos. $\mathrm{Na}$ verdade, é necessário colocar essas quantias no devido contexto. Os cidadãos americanos acreditam, por exemplo, que o seu país destina 15 a 20 por cento do seu Orçamento para a ajuda externa. Estão errados. Os EUA gastam menos de 1 por centro nessa ajuda, uma ninharia comparada com os milhões que o governo paga por ano aos fornecedores de armamento.

Um escritor sabe contar, não sabe fazer contas. Mas um economista amigo ajudou-me a fazer umas somas e gostaria de partilhar os resultados convosco. Com os 175 biliões de USD que os EUA já gastaram na guerra do Iraque desde Marco de 2003 seria possível fazer o seguinte:

1) Instalar 40.000 pequenas e médias empresas produtivas relativamente modernas e competitivas na África Sub-Sahariana, gerando directamente 12 milhões de novos postos de trabalho com salários e condições de trabalho acima da actual média. Deste modo se arrancaria de forma permanente cerca de 60 milhões de Africanos das malhas da pobreza. Além disto, este investimento tor- 
naria possível às economias africanas tirarem proveito efectivo das oportunidades comerciais que hoje já existem, como sejam o caso do AGOA (comércio preferencial com os EUA) e o EBA (everything-but-arms, comércio preferencial com a União Europeia). Isto significa que num espaço de tempo relativamente curto, o Produto Interno Bruto per capita da África Sub-Sahariana poderia ser triplicado, não à custa de ajuda mas com base em desenvolvimento e crescimento real da economia e uma melhor distribuição do rendimento gerado.

2) Além dessas empresas, com o dinheiro gasto no Iraque seria possível também construir mais 600 escolas técnico-profissionais de alta qualidade, onde poderiam ser formados, todos os anos, cerca de 300.000 trabalhadores qualificados para impulsionarem o desenvolvimento da agricultura, agroindústria, pesca, indústria, turismo, serviços, etc. Este treinamento permitiria que as empresas mencionadas acima pudessem funcionar bem com força de trabalho qualificada, com repercussões imediatas na produtividade e do nível de vida da maioria dos Africanos.

Ou refazendo as contas: os bilhões de dólares gastos no Iraque são suficientes para empregar mais 4 milhões de professores primários por um ano, ou para imunizar todas as crianças do Mundo contra diferentes doenças por 58 anos, ou para alimentar o Mundo durante os próximos 7 anos, ou ainda para terminar com o flagelo da malária em África e construir 2 milhões de novas habitações básicas.

Estes outros destinos a serem concedidos aos bilhões de dólares talvez fossem uma forma mais efectiva de combater a insegurança. Porque há um terror invisível que pode estar alimentando o terrorismo internacional. Esse é o terror da fome, da pobreza, da ignorância, o terrorismo do desespero perante a impossibilidade de mudar a vida.

Caros senhores,

Finalmente, quase nenhuma das nações desenvolvidas cumpriu aquilo que foi estipulado há trinta anos pelas Nações Unidas: destinar 0.7 por cento do seu orçamento para a ajuda externa. Em média, esse apoio não ultrapassa hoje os 0.25 por cento. Como se pode ver, não são apenas os países pobres que não estão cumprindo as obrigações internacionalmente assumidas.

O mais grave, porém, é que aquilo que nos é dado numa mão nos é retirado pela outra mão. Calcula-se que o proteccionismo e os subsídios retiram aos 
países pobres 2050 milhões de euros. Ou seja muitíssimo mais daquilo que é o valor da ajuda. Para além disso, os subsídios agrícolas na Europa e EUA representam um contra-senso na lógica que nos é imposta em relação aos mecanismos reguladores da economia. Numa palavra, os profetas do liberalismo de mercado não fazem em casa aquilo que propalam publicamente.

Mais grave ainda: está provado que 40 por cento do valor que se acredita dar aos países pobres é destinado a pagar a consultores internacionais. $\mathrm{Na}$ realidade, há hoje mais expatriados em África do que havia no tempo colonial. Quer dizer: uma parte do dinheiro está sendo absorvido pelo circuito dos países ricos. Com este dado, o valor da ajuda desce de 0.25 do orçamento para menos de 0.1 por cento. Afinal, não se está dando tanto quanto os cidadãos dos países ricos acreditam.

\section{O ciclo perpétuo da divida}

Os países africanos estão gastando e continuarão indefinidamente gastando mais a pagar o serviço da divida do que a investir na saúde ou na educação. De 1980 a 1990 a totalidade da divida da África sub-sahariana mais do que duplicou. Em 1995, as exportações somadas dos países africanos não chegavam para pagar o serviço da divida. A questão para eles já não era a de pagar ou não pagar, mas de sobreviver ou sucumbir.

Quando houver uma decisão sobre o cancelamento será demasiado tarde. Alguém já chamou à divida uma "guerra por outros meios". Essa agressão silenciosa não aparece na TV mas que é responsável pela morte de meio milhão de crianças em cada ano. Esta guerra faz da filantropia do Ocidente um falhanço anunciado e acabará por desacreditar um sentimento tão nobre como a solidariedade. Os mais miseráveis do continente - a quem se supõe ser destinada a ajuda internacional - pagarão, em cada ano, mais do que aquilo que estão recebendo. A verdade é simples: a divida é impagável. Nenhum país africano poderá exercer a sua independência sem que esse fardo tenha sido eliminado. Com este passado não pode haver futuro.

Quando o HIPC se decidiu em 1995 aliviar a divida de Moçambique nós festejamos. O anúncio do alívio foi feito com pompa e circunstância, um prémio a celebrar o nosso comportamento ajuizado. Afinal, era maior a festa 
que a razão de festejar. De 113 milhões por ano passou a pagar 100 milhões. Essa redução era, afinal, insignificante. Para se qualificar Moçambique teve que implementar medidas draconianas do Programa de Reajustamento Económico. Essas medidas tiveram impactos dramáticos no país. O tão propalado alívio acabou não libertando fundos que poderiam marcar a diferença no desenvolvimento de Moçambique.

Por outro lado, o que hoje se exige a Moçambique não se exigiu a países da Europa. Depois da grande Guerra, o chamado London Agreement aceitou que a Alemanha pagasse a divida acumulada aos aliados a uma taxa anual equivalente a 3.5 por cento dos seus rendimentos. Mais do que esse valor era tido como um factor de estrangulamento inaceitável. Porém, mesmo com a tal redução do HIPC, Moçambique pagará $13.5 \%$ do seu rendimento. O que quer dizer que estamos pagando 4 vezes mais que se achou aceitável a Alemanha pagar, numa situação de crise global e em que os preços das matériasprimas estão mais baixos do que nunca.

\section{Dar aos pobres a mesma chance de experimentar}

Os países pobres necessitam ter espaço para realizar os seus próprios debates e ensaios, experimentarem soluções ao seu próprio ritmo. Queremos ter a liberdade de, por exemplo, poder decidir qual o melhor momento para privatizar os serviços públicos. Essa liberdade foi, afinal, conferida aos europeus.

Instituições financeiras internacionais testaram nos países pobres fórmulas que se revelaram desastrosas. Parecia simples: tal como na receita socialista, uma mudança no sistema de propriedade mudaria toda a estrutura da economia. Produziram em embalagens de aplicação fácil os pacotes de reajustamento estrutural, formulas miraculosas que nos permitiriam evoluir queimando etapas.

A Moçambique também foi aplicada a mesma receita. Todos esses programas obrigaram a elevar preços pelos serviços públicos, a cortar subsídios e reduzir orçamentos para serviços sociais: toda esta receita resultou em crescente pobreza e desemprego. Hoje, é generalizado aceitar que esses programas não correram bem. Quem paga para recompensar os pobres dessa falhada experiência? 
O caso da castanha de caju de Moçambique é hoje tida como uma ilustração desses falhanços com efeitos catastróficos. Moçambique tinha e tem na castanha de caju um dos seus pilares de exportação. Em poucos anos o sector ficou arruinado, 80 por cento das fábricas fecharam e milhares de operários ficaram sem emprego. De um modo geral, a intervenção na agricultura pautou por uma ingenuidade crassa: a idéia de que intervindo nos preços se acabaria resolvendo tudo o resto.

Os actuais pacotes de redução da pobreza absoluta poderão ser a simples continuação, com outro vestuário, dos Programas de Reajustamento anteriormente falhados.

\section{Moralizar aquilo que se pode exigir aos outros}

Parte dos que nos pedem não é historicamente realizável. Os países mais pobres devem liberalizar as suas economias num período mais curto do que foi alguma vez exigido aos países desenvolvidos. Algumas vezes, coloca-se como condição de libertação dos fundos o cumprimento de metas que são impraticáveis. Espera-se que façamos em 5 anos aquilo que outros levaram séculos a alcançar. Algumas das nações européias que nos cobram pela descentralização estão muito longe de cumprir, elas próprias, esse processo de descentralização.

Alguns dos que hoje nos exigem clareza, transparência e boa governação apoiaram golpes de Estado em África, patrocinaram o assassinato de líderes e apoiaram agressões a regimes sob o único pretexto de estarem do lado errado no período da Guerra Fria. Ainda hoje a ajuda que se ergue como um "dever moral" continua sendo condicionada politicamente. Quem fala, por exemplo, da ditadura infame da Guiné Equatorial ? Em 1994, a embaixada dos EUA fechou e os americanos romperam com o regime da Guiné Equatorial por acharem inaceitável o regime de Teodoro Obiang. Um ano depois, quando foram descobertas importantes jazidas de petróleo, os EUA regressaram correndo, aceitando aquilo que antes era intolerável. O petróleo é um poderoso diluente de ditaduras.

Algumas das vozes que reclamam moralidade dos regimes africanos estiveram caladas perante a injustiça do apartheid. Ao menos, o meu pequeno 
país foi capaz de se erguer não apenas contra o poderoso apartheid sul-africano mas contra o regime rodesiano de Ian Smith. Para defendermos essa coerência de princípios perdemos 17 bilhões de dólares, considerando apenas os custos directos da desestabilização lançada contra o nosso país. Esse divida financeira e moral não entrará nas contas com a chamada comunidade internacional. Como não entrará nas contas a guerra de desestabilização que por quase duas décadas martirizou a nação moçambicana. Hoje fala-se de guerra civil em Moçambique como se esse conflito tivesse tido apenas contornos endógenos. É preciso não esquecer nunca: essa guerra foi gerada no ventre do apartheid, estava desde o início inscrita na chamada estratégia de agressão total contra os vizinhos da África do Sul.

No meu país o espectro do terrorismo não começou com o Onze de Setembro. Milhares de crianças estão desde há mais de vinte anos espreitando com medo o chão que vão pisar. Mais de um milhão de minas antipessoais foi semeada durante a guerra. Milhares desses engenhos mortais continua semeando o terror no seio de cidadãos inocentes. Quantos dos países ricos que se mobilizam contra terrorismo assinaram a convenção para o banimento da produção de minas?

\section{O convite para a simulação}

A resposta a tudo isto, é claro, deveria vir de dentro dos países pobres. Teríamos que ter agenda, própria, uma estratégia nossa. Forçados a sobreviver no imediato vamos investindo naquilo que são chamadas as "sound policies": o que é bom é privatizar, descentralizar, cumprir os indicadores da macro-economia. Mesmo sabendo que isso corresponde a a uma encenação para agradar aos doadores. É mais importante obedecer cegamente a um valor estipulado para a taxa de inflacção do que criar condições de emprego. Estamos produzindo um ambiente económico e social propício para nos qualificarmos para mais ajuda, em vez de criarmos um ambiente propício para o nosso desenvolvimento.

As palavras da moda vão-se sucedendo num léxico descartável: "comunidades locais", desenvolvimento sustentável, assuntos de géneros, sociedade civil, povos indígenas, comunidades tribais. Nem sempre se entende a subs- 
tância concreta dessas palavras. Mas elas conduzem a um jogo de sedução reciproca, a uma infindável encenação teatral. Não tarda que nos nossos países - esses a quem se ordena que emagreçam o Estado - surjam Ministérios para a Sociedade Civil, Ministérios das ONGs, Ministérios para a sustentabilidade.

Caros amigos,

Em 1984 eu estava na minha varanda quando vi chegar a tempestade. $\mathrm{Na}$ altura não tinha nome, mas uma enorme ventania fez levantar poeiras no chão e ondas no mar, misturando granizo e vento, quebrando vidros, erguendo tectos, espalhando destruição. Depois, o fenómeno levou nome, um nome de mulher como convém a qualquer tempestade que se digne. A tempestade foi chamada de DOMOINA. A minha angústia perante os destroços era: como nos vamos reerguer, em plena guerra e no meio da maior miséria? Mas a solidariedade interna, ainda assim, deitou semente e colheu fruto. Os apoios vieram de dentro e o país encontrou ainda força para se levantar. Em pouco tempo, as feridas estavam curadas e cicatrizadas.

Falamos aqui da cooperação de Moçambique com a Europa e com o Mundo. Mas a primeira grande questão seria como é que Moçambique está cooperando consigo mesmo? Como é que se promove o desenvolvimento a partir de dentro? Este debate tem que ser conduzido dentro de África. Ele já está nascendo com a emergência de jovens que não se satisfazem com o discurso saturado da culpabilização dos outros sempre que analisa a situação interna do continente. O maior desastre de África não é ser pobre mas ter sido empobrecida pela aliança entre a mão exploradora de fora e a mão conivente de dentro.

Trinta anos a pedir apoio cria uma dependência mental que anula o espírito do 25 de Junho. Há toda uma geração de quadros que já raciocina em função do que e a quem se vai pedir. Estamos criando Junhitos, gente que se sonha doméstica e domesticada. O mais grave é que a reprodução dos Junhitos se faz dentro de Moçambique, de forma endógena e indígena.

África não é o continente dos outros, um simples dever moral, um assunto de retórica diplomática. É verdade que compete aos africanos reconquistarem a sua credibilidade como parceiros. Mas os africanos não poderão fazêlo no quadro actual da governação mundial. A verdadeira ajuda será não dar 
mais mas lutarmos juntos, europeus e africanos, para mudar esta teia de relações. Precisamos de uma ajuda que nos torne menos dependentes da ajuda, temos que construir uma dependência progressivamente menos dependente.

Por enquanto, o que vamos fazendo nós, doadores e receptores, é tocar a duas mãos uma valsa que esconde uma irresolúvel agonia. No final, o continente africano poderá ter mais algumas escolas, mais alguns hospitais. Mas não terá gerado recursos próprios nem desenvolvido as forças produtivas.

Há 30 anos os moçambicanos venceram um poderoso exército desencadeando uma luta de pequenos grupos de guerrilha. Ainda hoje as vitórias que conseguirmos serão por via dessa persistência guerrilheira. Não há grandes soluções, grandes reviravoltas que façam endireitar o eixo da Terra. A nossa soberania (e também a vossa soberania) está nessa fresta, nesse intervalo. $\mathrm{O}$ que necessitamos é de um maior diálogo, maior comparticipação e reciprocidade dos mecanismos de controle dos dinheiros e dos compromissos assumidos. O que necessitamos é de nos tornarmos parceiros de verdade.

Termino confessando-vos um sonho, um desejo. Os trinta anos de Independência não são apenas um momento já vivido. São um tempo vivo cujas potencialidades ainda se irão revelar por inteiro. O nosso passado, desde 1975, é um futuro. Uma semente que está dando árvore. Queremos ter direito à sombra dessa grande árvore. E queremos partilhar essa promessa de felicidade com os nossos irmãos da Suíça. Porque também eles, os suíços, nos ajudar a semear esse futuro. 